\title{
AN EVALUATION OF JUTE-EPOXY-HYBRID COMPOSITE MATERIALS FOR AUTOMOTIVE FRONTAL CRASH SAFETY APPLICATIONS
}

\author{
Suresh Babu K ${ }^{1}$, Somashekar H K ${ }^{2}$, S Padmanabha ${ }^{3}$ \\ ${ }^{I}$ Student, Department Of Mechanical Engg, Brindavan College Of Engg, Bengaluru, Karnataka, India \\ ${ }^{2}$ Assistant Professor, Department Of Mechanical Engg, Brindavan College Of Engg, Bengaluru Karnataka, India \\ ${ }^{3}$ Principal, Department Of Mechanical Engg, Brindavan College Of Engg, Bengaluru, Karnataka, India
}

\begin{abstract}
The present work evaluates the occupant safety and the mechanical behavior of the Jute-Epoxy-Glass hybrid composite materials and to carry out dynamic analysis of an automobile car frontal components like Bumper beam by using Jute-Epoxy-Glass Hybrid composite material by FE approach. In the present study, HYPERMESH and LS-DYNA software is employed to obtain a better composite material. Durability, NVH, Crash safety and Aesthetics are some of the important vehicle attributes that need to be meet the vehicle manufacturer. While the crash safety for NHTSA requires the G level should be less then 40G'S at the occupant seat. Initially manufacturing of 4 ply, 6 ply (Jute-Epoxy) and 5 ply (Jute-Glass-Epoxy) laminates is done and there characterization is done under Quasi static (1 $\mathrm{mm} / \mathrm{min})$ and Impact High strain rate loading (100mm/min and 200mm/min) for tensile tests. The mechanical properties obtained are set for the existing bumper beam of a meshed model. For bumper beam of a car with a given velocity of $56 \mathrm{~km} / \mathrm{h}$ according to the NHTSA high speed crash test. For a high speed crash speed test of bumper beam the $G$ levels is taken into consideration so that the $G$ levels acting upon the occupant doesn't cross 40 G'S as safer. The results obtained from high strain rate of $200 \mathrm{~mm} / \mathrm{min}$ tensile tests explore to bumper beam for which $G$ level acting on the occupant is 35 G's for hybrid jute glass epoxy with $6 \mathrm{~mm}$ thickness which is found to be best suited composite material which is safer for the occupant and also the weight reduction is also considered where conventionally used steel is $6.6 \mathrm{kgs}$ and the hybrid material of Jute-Glass-Epoxy is $2.9 \mathrm{kgs}$ these weight savings leads to fuel efficiency of the car.
\end{abstract}

Keywords: Hybrid composites, NHTSA, Ls-Dyna, High strain rate And G levels etc...

\section{INTRODUCTION}

With the quick growth of the skills and knowledge of composite materials there is a need for available certification of their structure, properties and the addition of structure property relation with processing design and fabrication. In the past glass fiber reinforced polymer composite materials where used by Chevrolet Corvette at New York in 1953 to make a car body. Till now the Theorvette succession employ composites in their manufacturing design. These days Formula series cars and other racing cars uses composite materials in enormous quantity in roughly for all the car parts. Composite materials contain a lot of compensation greater than the usual materials because of comparatively elevated strength and less mass and also superb corrosion resistances and dimensional permanence additional resistance for crashes and fatigue also additional static and dynamic masses of the car body. Because of These compensation would boost the act of cars and guide to safer and lesser energy utilization. The car performance simply not affected because of engine horsepower, other than that additional parameters like mass/horsepower ratio and fine sharing of the mass. light weight vehicles will leads to decrease in energy consumption and as been expected that the fuel economy gets better by $8 \%$ for each $12 \%$ of mass decrease for total weight of the vehicle. During any of the crashes maximum energy should be absorbed by structure keeping the of the passenger seat within the suitable limit such that structure should be stiff in some portions to avoid intrusions into susceptible areas such as the passenger cabin and fuel system and also must be yield in other portions to absorb the developed force energy before reaching to the stiff portion.

\subsection{Frontal Collision}

As many of us use automotive car which as became one of the basic need for human being in this world to represent their status even though the petrol or diesel price is growing higher and higher day by day mean while accident are becoming more and more on each corners of this world. The collision or the impact for a rigid wall and a car which is travelling in opposite direction is as shown in fig 1 When the collisions is offset at a lesser the vehicle size comes in contact. The car should be design in such a way that the safety features, especially in frontal zones because large forces drawn in the frontal impacts. Frontal impact crash is more when compare to other crashes even at low speed say $20 \mathrm{~m} / \mathrm{h}$ the impact here is staggering. Frontal collisions may occur when the driver drowsiness and lack of concentration on a highway or causal aspect like cars going with the flow 
onto the wrong side of the path another important issue is a overtaking.

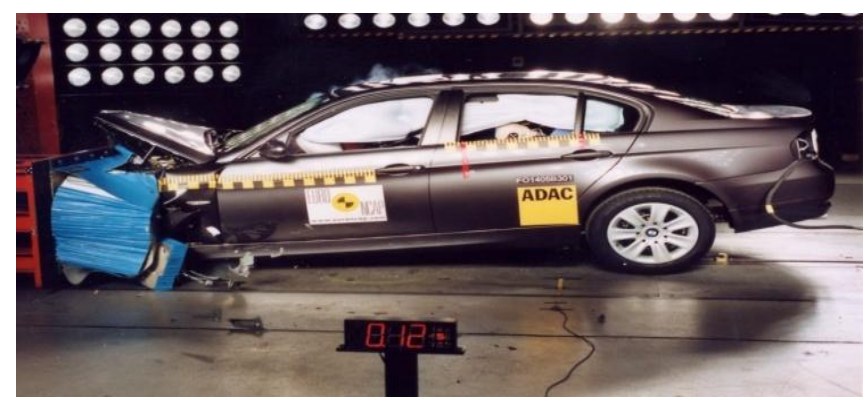

Fig -1: Side view of a frontal impact

\subsection{Safety Standards Criteria}

NHTSA which stands for National Highway Traffic Safety Administration which has been recognized in 1970 by the Highway Safety Act and is keen for achieving the maximum principles of merits in motor vehicle and highway safety. It is used to avoid collision and their assistant costs, both as financial and human.

FMVSS 208 stands for Federal Motor Vehicle Safety Standards which is one of NHTSA's principal safety programs. Each standard as certain types of motor vehicles requirements or vehicle parts sold in the United States to meet up specified safety performance levels. Standard performance tests that can be carried out under controlled conditions. Any moderation system that meets the test requirements could be installed in the Standard. These installed standards have proved feasible, producible and able of meeting the test requirements.

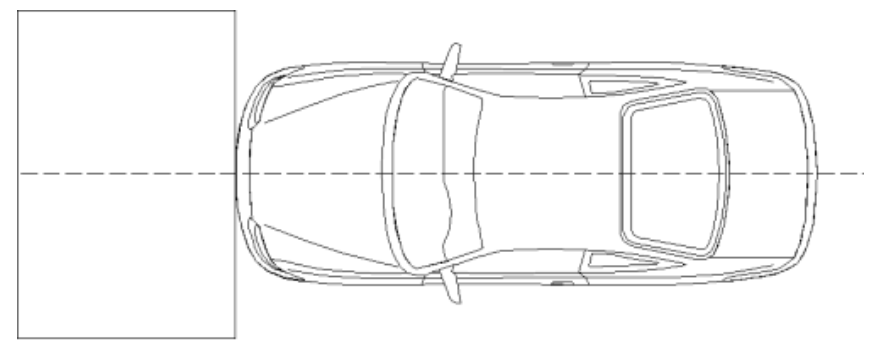

FMVSS No. 208

Fig -2: FMVSS 208 for frontal impact crash safety

\subsection{Crashworthiness and Its Requirements}

Occupant Safety Crashworthiness is the assess that how sound a vehicle provides protection to its occupants during a collusion. The crash which results from the two cars is frequently cruel. Therefore there is a need to address the occupant safety cras1hworthiness requirements during the earlier design phase of an automotive. In USA there is are stringent requirements on the part of the vehicle manufacturer to meet up the regulations and a few specific tests are accepted by Global New Car Assessment Programme (NCAP) before introduction of new vehicle. Recently the tests were performed on car: Tata Nano,
Maruthi 800, Hyundai i10, Ford Figo, Volkswagen polo where belongs to the manufacturer of India by the London car safety NCAP and found that all five cars failed which were Landing to zero on a scale of 1 to 5 .

The Federal Vehicle Motor Vehicle Safety Standards adopts the frontal rigid barrier collision test to evaluate the standard for crashworthiness as occupant safety. This performance specifies the standards for the severity of injuries on the road vehicle and the vehicle occupant. These is skillful by specifying crashworthiness of the vehicle necessities as force and deceleration capacity on a 50th percentile Hybrid dummy as a human surrogote in collide as shown in fig 3 . and by specifying active and passive restraint requirements.

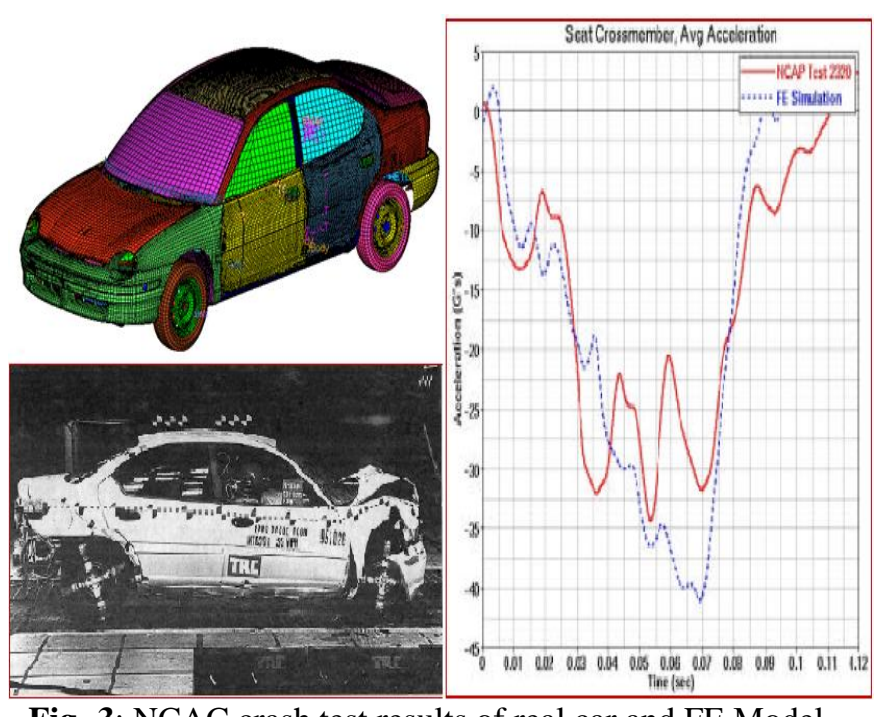

Fig -3: NCAC crash test results of real car and FE Model w.r.t (G'S) and (sec)

\subsection{Automotive Safety Requirements}

There are high speed impact and low speed impact test requirements that a vehicle need to meet. The following are the current norms that are followed in USA :

$>$ Low speed impact test where conducted at $4 \mathrm{~km}$ per hour with no damage to the bumper. After conducting low speed impact analysis, any dent to the bumper chart and functional should not take place.

$>$ High speed impact experiment, Here the bumper scheme have to absorb enough energy to meet up bumper regulars in design phase. No bumper damage or yielding after $8 \mathrm{~km}$ per hour for frontal crash into a stiff barrier.

$>\quad$ The accelerations on the occupant should not exceed $40 \mathrm{G}$ levels during a frontal collision, When the vehicle hits a rigid barrier with a speed of 35 miles/hour according to FMVSS

Crash tests to be compulsory for all new cars from October 2017. Passing minimum frontal and side crash tests will be compulsory for all new cars. While From 2017 for new vehicles of existing models the cut-off date will be October 2019. 


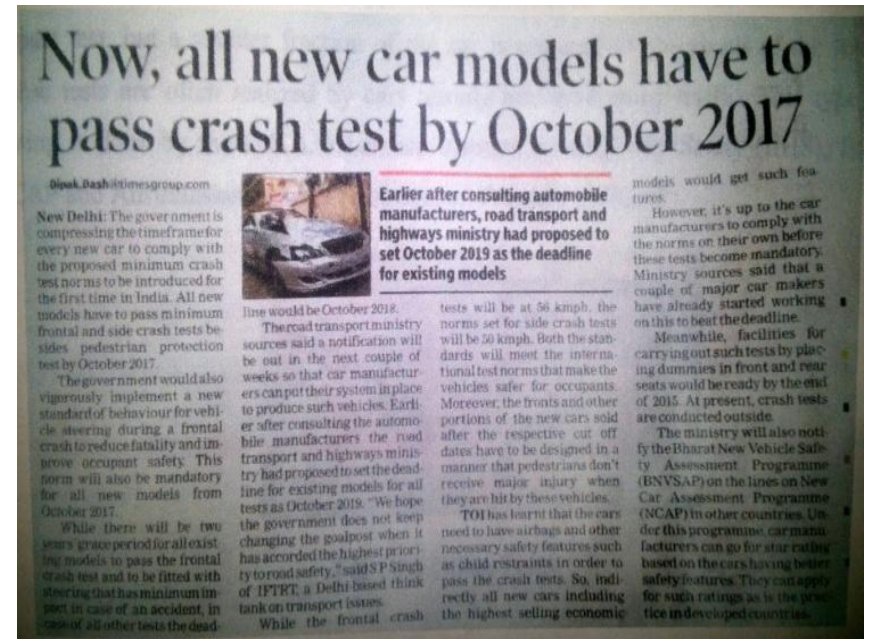

Published in Times Of India on 1st March 2015

\subsection{Bumper Beam}

The bumper beam plays an vital function in energy absorbing component and to give protection to the other components to keep the occupant in safe condition. composite materials for bumper beam as become common because of low weight and low volume vehicle. The main role of bumper beam is to take up $\mathrm{K}$ E during frontal collusion. There are several factor should be considered while choosing the material for cars bumper beam like Energy absorption, Performance, Weight, Service Condition, Cost, Availability of material, Environmental condition and Manufacturing process.

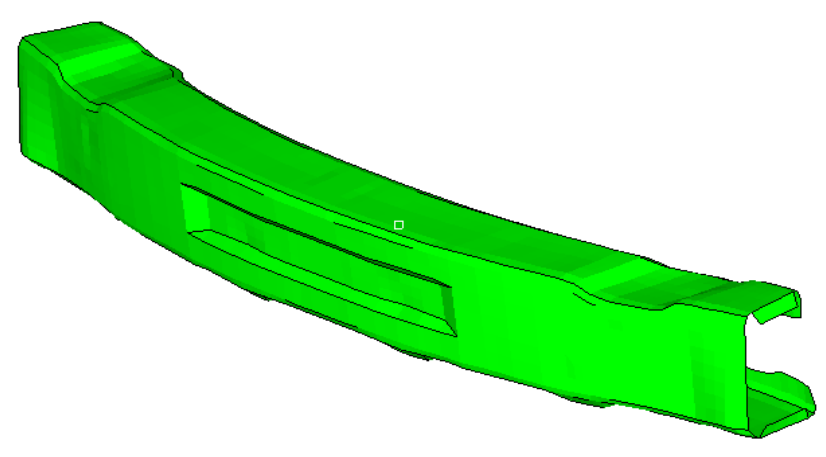

Fig-4: Bumper beam

\section{LITERATURE REVIEW}

S Prabhakaran et al. [4], In his study the glass fiber epoxy is fabricated and designed for automotive bumper beam and compared with present using steel material. He has took a $40 \mathrm{~mm}^{2}$ area of both steel and fabricated glass fiber epoxy and conducted a charpy test and found that impact strength is more when compare to steel and also weigh saving cost etc. Rejaul Hasan and Rishad Rayyaan [6], In this paper studied the outcome of fiber geometry for tensile properties of thermoset jute fiber composites. He took different types of reinforcement like non-woven, woven, and carded silver and found that woven type fiber has higher strain, young's modulus and high strength when compare to other two fibers Yehia A. et al. [13] In his article frontal collision simulation of motor vehicle demonstrated in opposition to lighting column to inspect for injury and possible of safety. Design is made on the lighting column, the column with slighter thickness , the slighter is the energy absorption by the motor vehicle or the safety occupant of the motor vehicle. High impact on the small area of the car leads to high risk of injuries as well as vehicle occupants. Modern designed car are of composite materials that absorbs most of the residential energy resulted from impact. high yield strength of the material obsorbs little impact energy in turn high injuries A. Hambali et al. [16] in his paper totally 6 different composite materials were used which are mainly suitable for cars bumper beam manufacturing by taking into account eight major parameters and also twelve sub parameters. The AHP study established that the fiberglassepoxy is the suitable composite because these material has the maximum point of $26 \%$, weight fraction when compared with other materials and resulted that the fiberglass epoxy is the majority best choice.

\section{OBJECTIVE}

The aim assignment of these work is to evaluate for occupant safety and the mechanical behaviour of the JuteEpoxy-Glass hybrid composite materials and to carry out dynamic analysis of an automobile car frontal components like Bumper beam and Bumper fascia by using Jute-EpoxyGlass Hybrid composite material by FE approach. FEM in general is commercial FEA software in particular implemented on a personal computer offers a universal tool for cost effective analysis. In the present study, HYPERMESH and LS-DYNA software is employed to obtain a better composite material. The work is associated with the manufacturing of 4 ply and 6 ply of Jute Epoxy and also 5 ply Jute Glass Epoxy hybrid composite materials and this materials are tested for tensile tests the mechanical properties obtained are set for the existing bumper beam and bumper fascia for a meshed model which is downloaded NCAC website. For bumper beam of a car is given with a velocity of $56 \mathrm{~km} / \mathrm{h}$ according to the NHTSA high speed crash test. For a high speed crash speed test of bumper beam the $G$ levels is taken into consideration so that the $G$ levels acting upon the occupant doesn't cross $40 \mathrm{G}$ 'S as safer. The main aim of the experiment is to present a new material for bumper beam which reduces the weight and also to investigate the strength and G levels and for bumper beam. various other parameters needed to determine dynamic strength of composite automobile frontal crash application.

\section{FABRICATION}

The manufacturing of jute epoxy composite are manufactured by the hand layup technique. The bidirectional jute fiber are used as reinforcement and epoxy is taken as matrix material. The Hardener and the Epoxy resin are purchased from the S S Polymers Bangalore. The reinforcement is chosen based on its availability, impact strength, tensile strength, cost and the most important aspect is a weight reduction. In these process the matrix material has been selected based on their consideration to the chemical reaction and compatibility with the reinforcement, 
its ability to wet the reinforcement and to its own characteristics properties and processing behavior. The fig 5 shows the standard dimensions for the tensile testing, as per the ASTM standards D 3039/D 3039M. The length of sample is $200 \mathrm{~mm}$ and width is $20 \mathrm{~mm}$. For high strain rate, the specimen dimension of length $200 \mathrm{~mm}$, width $25 \mathrm{~mm}$ and for holding $45 \mathrm{~mm}$ length at both ends of the specimen in both the cases
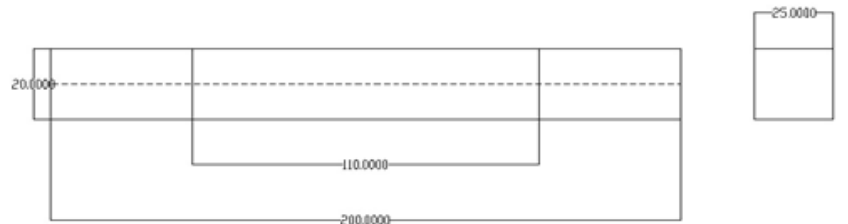

Fig -5: Standard Dimension specimen used for tensile testing in $\mathrm{mm}$

\section{DEVELOPMENT OF CALIBRATED FE}

\section{MODEL}

The dodge neon model used for the analysis is a four-door with a dummy inside. It is developed by NHTSA and the below Fig 7.1 shows the finite element model of Dodge Neon used for validating the design automotive structure for frontal impact safety. The model is downloaded from the link http://www.ncac.gwv.edu/vml/model.html. It has 462 components, which represent various parts of vehicle and these are joined together by spot-weld and rigid body constrained options.

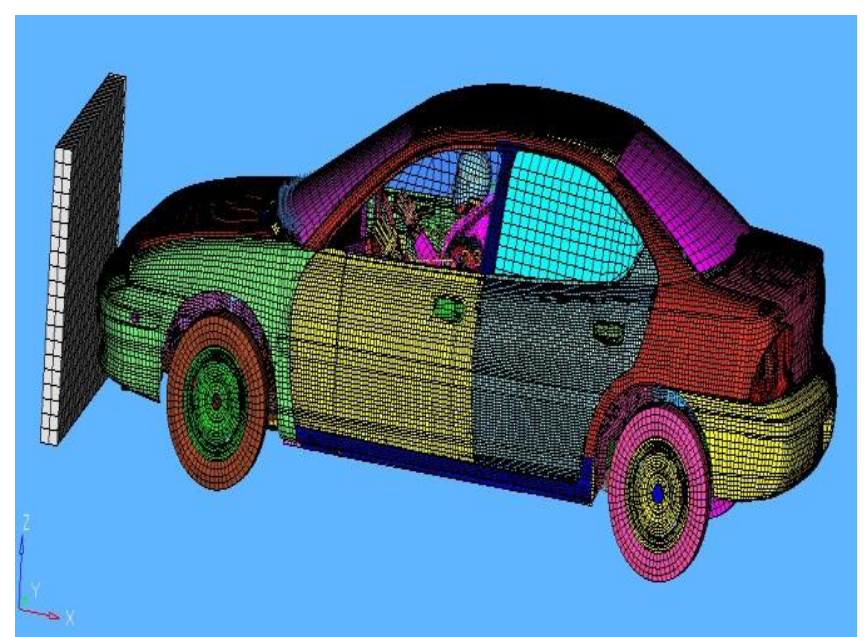

Fig -5: Side view of meshed dodge neon model car with dummy inside

The car modeling and meshing is not an easy task and also it is not a single engineers work. The developing of this model takes an year for five to six engineers. The available model has been used for crash analysis in this project. The is imported in hypermesh software tool and checked for spot welds and the missing components. The spot welds are added at the required location and required components are added at the requires location.

\subsection{Ls-Dyna Dynamic Analysis for Bumper Beam at High Speed of $56 \mathrm{~km} / \mathrm{h}$}

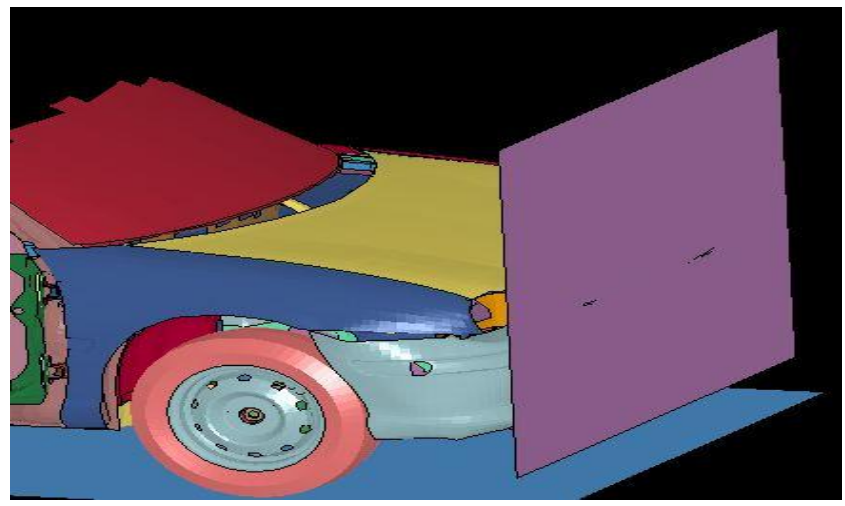

Crash Time at $0.04 \mathrm{sec}$

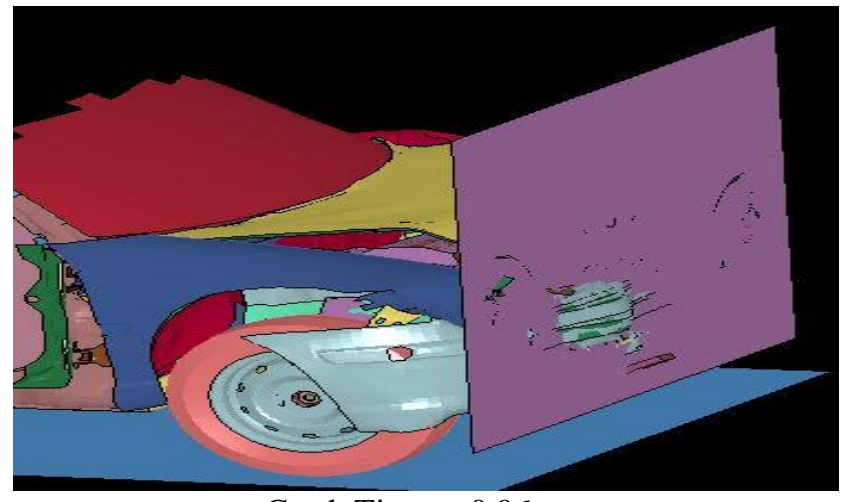

Crash Time at $0.06 \mathrm{sec}$

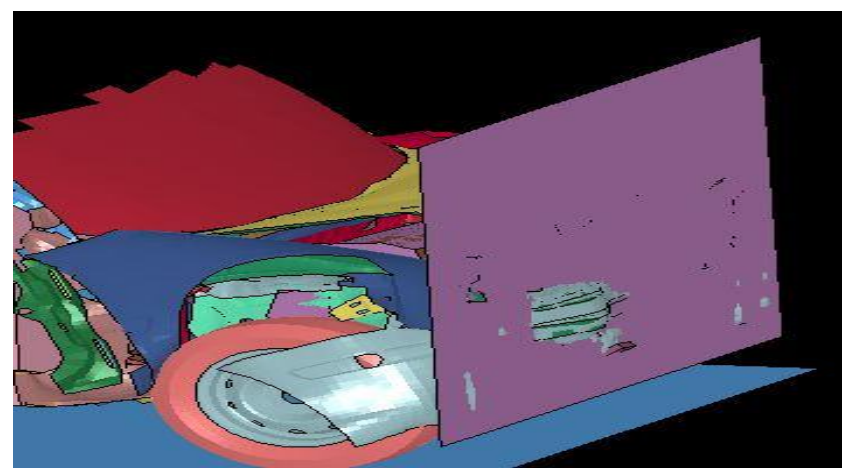

Crash Time at $0.09 \mathrm{sec}$

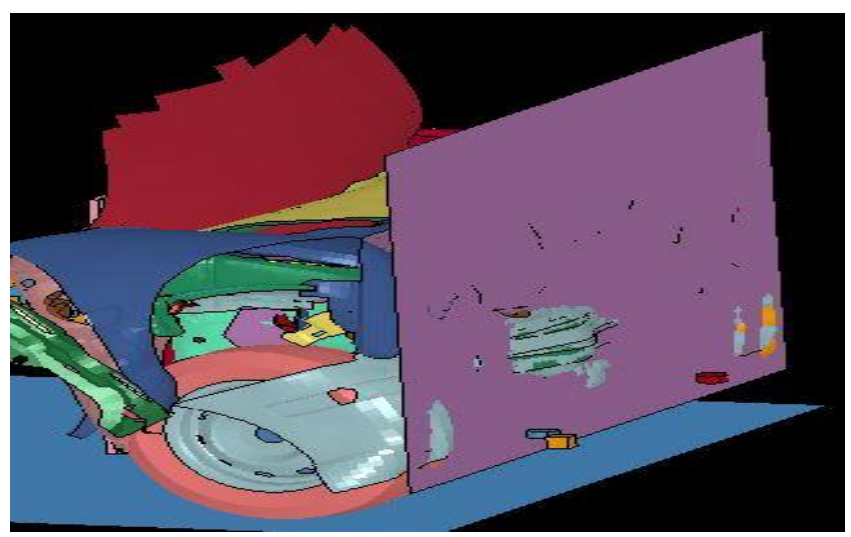

Crash Time at $0.15 \mathrm{sec}$ 


\section{RESULTS AND DISCUSSIONS}

\subsection{Results from Tensile Testing Graph}

$>$ It is noted that with increase in the rate of loading the strength has increased and The peak strength increases with the loading rate increase from $1 \mathrm{~mm} / \mathrm{min}$, $100 \mathrm{~mm} / \mathrm{min}$ and $200 \mathrm{~mm} / \mathrm{min}$ for 4 ply, 6 ply and 5 ply.

$>\quad$ For a 5 ply with adding up of glass fiber the peak stress of the laminates increases tremondeously

$>$ With reising in fiber volume fraction the strength increased conssiderably, when the fiber volume fraction has increased from $37 \%$ to $46 \%$. by this the strength increased by $25 \%$

$>$ Increasing the plies for hybrid material with increasing the thickness the material gets high impact strength.

\subsection{Results from Ls-Dyna Explict for Bumper}

\section{Beam}

\subsubsection{Dynamic Analysis For 5ply Jute-Glass-Epoxy}

\section{Composite material with $6 \mathrm{~mm}$ Thickness}

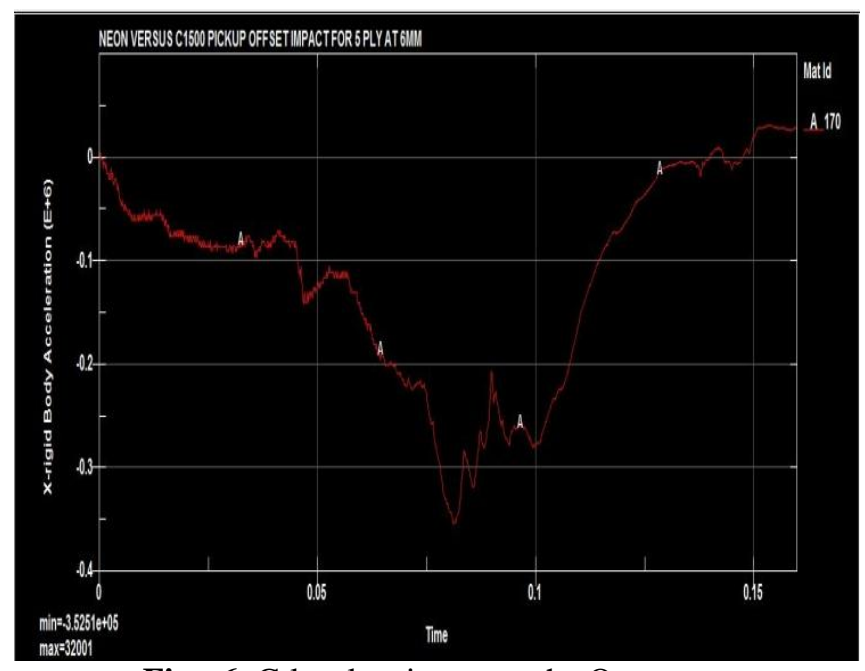

Fig - 6: G level acting upon the Occupant

\subsubsection{Dynamic Analysis For 4ply Jute-Epoxy}

\section{Composite material with 6 mm Thickness}

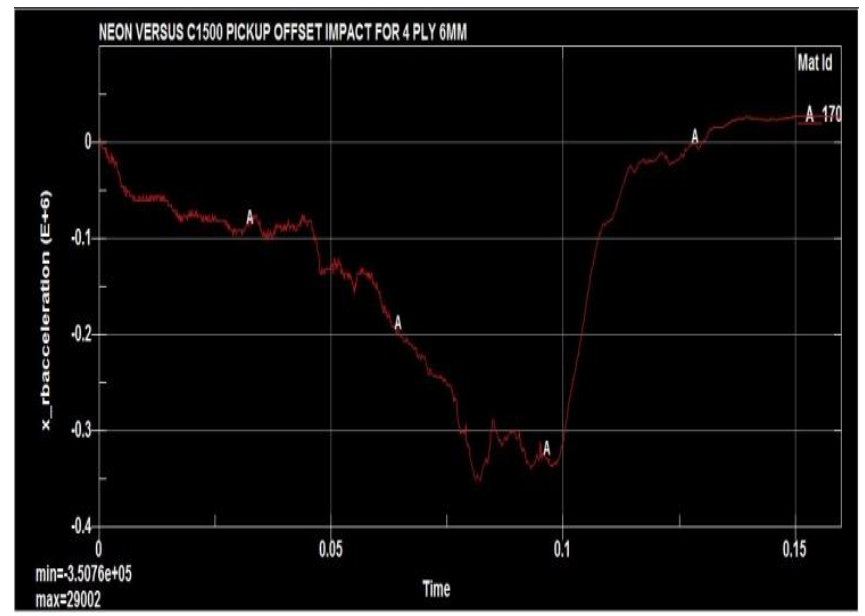

Fig - 7: G level acting upon the Occupant
The fig 6 shows the results of Acceleration Vs Time for automotive Bumper beam and found the minimum $G$ level is - $3.525 \mathrm{e}^{5}$ which is the second units according to Ls-Dyna manual i.e $\quad 3.525 \times 10^{5} \mathrm{~mm} / \mathrm{sec}^{2}$

$3.525 \times 10^{2} \mathrm{~m} / \mathrm{sec}^{2}$

$352.5 / 9.81 \mathrm{~m} / \mathrm{sec}$

$35.93 \mathrm{G}$ Levels

From fig 7 The G levels for 4 ply Jute-Epoxy with $6 \mathrm{~mm}$ thickness is $35.75 \mathrm{G}$ 'S

\subsection{Fe Analysis Results and Discussion}

Table 2 G Levels and Weight Reduction For Bumper Beam

\begin{tabular}{|c|c|c|c|c|c|}
\hline $\begin{array}{l}\text { SI } \\
\mathbf{N} \\
\mathbf{0}\end{array}$ & $\begin{array}{l}\text { Materia } \\
\text { ls }\end{array}$ & $\begin{array}{l}\text { Volu } \\
\text { me(m } \\
\left.\mathbf{m}^{3}\right)\end{array}$ & $\begin{array}{l}\text { Densi } \\
\text { ty }(g / c \\
\text { c) }\end{array}$ & $\begin{array}{l}\text { Mass } \\
\text { of The } \\
\text { Bumpe } \\
\text { r } \\
\text { Beam } \\
\text { (kgs) }\end{array}$ & $\begin{array}{l}\text { G } \\
\text { levels } \\
\text { Acting } \\
\text { Upon } \\
\text { the } \\
\text { Occupa } \\
\text { nt } \\
\text { (m/sec) }\end{array}$ \\
\hline 1 & Steel & $\begin{array}{l}84474 \\
4.569\end{array}$ & 7.8 & 6.62 & 41 \\
\hline 2 & $\begin{array}{l}4 \text { ply } \\
\text { Jute- } \\
\text { Epoxy } \\
(3.2 \mathrm{~mm})\end{array}$ & $\begin{array}{l}84474 \\
4.569\end{array}$ & 1.7 & 1.52 & 44.68 \\
\hline 3 & $\begin{array}{l}6 \quad \text { ply } \\
\text { Jute- } \\
\text { Epoxy } \\
(4.6 \mathrm{~mm})\end{array}$ & $\begin{array}{l}84474 \\
4.569\end{array}$ & 1.7 & 2.18 & 43.23 \\
\hline 4 & $\begin{array}{l}5 \text { ply } \\
\text { Jute- } \\
\text { Glass- } \\
\text { Epoxy } \\
(2.6 \mathrm{~mm})\end{array}$ & $\begin{array}{l}84474 \\
4.569\end{array}$ & 1.7 & 1.23 & 48.56 \\
\hline 5 & $\begin{array}{l}4 \quad \text { ply } \\
\text { Jute- } \\
\text { Epoxy } \\
(6 \mathrm{~mm})\end{array}$ & $\begin{array}{l}84474 \\
4.569\end{array}$ & 1.7 & 3.2 & 35.75 \\
\hline 6 & $\begin{array}{l}5 \quad \text { ply } \\
\text { Jute- } \\
\text { Glass } \\
\text { Epoxy } \\
(6 \mathrm{~mm})\end{array}$ & $\begin{array}{l}84474 \\
4.569\end{array}$ & 1.7 & 2.9 & 35.93 \\
\hline
\end{tabular}

The aim of the project is to reduce the weight of Bumper beam for the same strength of existing material and also to reduce the $G$ level acting upon the Occupant. The volume, density, weight of the bumper beam and $G$ levels acting upon the occupant is as listed in table 1 . The weight of the steel is $6.62 \mathrm{kgs}$ where the weight and Jute Glass Epoxy is $2.9 \mathrm{kgs}$ so the weight reduced by an amount of $62 \%$. and the occupant $\mathrm{G}$ levels have come to $35 \mathrm{G}$ 's 


\section{CONCLUSION}

From the study it can be concluded that agriculture product like Jute fiber are able to use for the fabrication of composite and able to make agricultural Product into useful engineering applications. The peak strength increases with the loading rate increase from $1 \mathrm{~mm} / \mathrm{min}, 100 \mathrm{~mm} / \mathrm{min}$ and $200 \mathrm{~mm} / \mathrm{min}$ for 4 ply, 6ply and 5 plyWith adding up of glass fiber to the laminates the peak stress of the laminates increases tremondeouslyWith rising in fiber volume fraction the strength increased conssiderably, when the fiber volume fraction has increased from $37 \%$ to $46 \%$. by this the strength increased by $25 \%$.The weight of the Bumper beam reduces from $6.62 \mathrm{kgs}$ of steel to $2.9 \mathrm{kgs}$ of Jute Glass Epoxy Hybrid composite material with $62 \%$ of weight reduced. The $\mathrm{G}$ levels acting upon the occupant safety with the steel of 40 G's is brought below to $35 \mathrm{G}$ 's with the Jute Glass Epoxy Composite materials. The Stresses induced for bumper fascia with Fiberglass plastic flux resin is nearer to the stress of Jute Glass Epoxy. Most Importantly the price for Bumper beam of steel is about 8000 rs and the Jute Glass Epoxy is about 3000 rs nearly $70 \%$ of savings.

\section{SCOPE FOR FUTURE WORK}

The Jute and Jute Hybrid composite material with more thickness and using more plies so that the G level may come to below $40 \mathrm{G}$ levels. The 6 ply Jute Epoxy is suitable for instrument panel and can be used for other automotive application like A pillars, B pillars, and even for $\mathrm{C}$ and $\mathrm{D}$ pillars for automotive side impacts, If the $G$ levels is crossing above 40 for any of the above mentioned pillars then increase the plies and thickness. Additional studies can be carryout with the nature of static analysis. Optimization of geometry can be done to improved .Possibility to produce composites with higher percentages of Jute and Glass can be studied. Corrosion property and other thermal properties can be studied .Different types of Tests are to evolved to study more mechanical properties.

\section{REFERENCES}

[1] Burke, "Injuries Sustained by Motor Vehicle Occupants", Forensic Medical Investigation of Motor Vehicle Incidents, 2006.

[2] Rush K C," An overview of automotive plastic bumpers, in automotive bumper system and exterior panels [R]", SAE Technical Paper, 900420, 1990.

[3] Biswas S., Kindo S., Patnaik A., "Effect of Length on Coir Fibre Reinforced Epoxy Composites, Fibre and Polymers 12", pp. 73-78. (2011).

[4] S. Prabhakaran, K. Chinnarasu, M. Senthil Kumar, "Design and Fabrication of Composite Bumper for Light Passenger Vehicles" International Journal of Modern Engineering Research (IJMER), Vol.2, Issue.4, July-Aug. 2012 pp-2552-2556

[5] Gowda, T. M., Naidu, A. C. B., \& Chhaya, R." Some Mechanical Properties of Untreated Jute FabricReinforced Polyester Composites", Composites Part A: Applied Science and Manufacturing, Vol.30(3), pp. 277-284, (1999).
[6] Rejaul Hasan and Rishad Rayyaan, "Effect of fibre geometry on the tensile properties of thermoset jute fibre composites" International Journal of Scientific and Research Publications, Volume 4, Issue 10, October 2014.

[7] .Chawla, K. K. \& Bastos, A. C, "The mechanical properties of jute fibres andpolyester/jute composites". In: Proceedings of the third international conference on mechanical behaviour of materials. Cambridge, UK: Pergamon Press, pp. 191196. (1979).

[8] Karmaker, A. C. \& Schneider, J. P."Mechanical Performance of Short Jute FibreReinforced Polypropylene". Journal of Materials Science Letters, Vol. 15(3), pp. 201-202. (1996).

[9] Ajith Gopinath, Senthil Kumar.M, Elayaperumal, " Experimental investigations on mechanical properties of jute fiber reinforced composites with polyester and epoxy resin matrices ", A procedia engineering 97 (2014) 2052-2063.

[10] Wang, Y., Li, J. \& Zhao, D, "Mechanical properties of fibre glass and Kevlar woven fabric reinforced composites", Composites Engineering,Vol.5(9), pp.1159-1175. (1995).

[11] Girisha.C., Sanjeevamurthy. \& Gunti Rangasrinivas, "Tensile Properties Of Natural Fibre-Reinforced Epoxy-Hybrid Composites", International Journal of Modern Engineering Research, Vol.2(2), pp-471474, .(2012).

[12] Velmurugan, R. \& Manikandan, V, "Mechanical properties of palmyra/glass fibre hybrid composites", Composites Part A: applied science and manufacturing, Vol.38 (10), pp.2216-2226, (2007).

[13] Yehia A. Abdel-Nasser, " Frontal crash simulation of vehicles against lighting column using FEM", exanderia engineering journal 52, 295-299, (2013)

[14] Dagmar G. Buzeman, David C. Viano and per lovsundaccid. anal and prev., " Car occupant safety in frontal crashes: parameter study of vehicle mass, impact speed and inhernt vehicle protection ",vol .30,no 6,pp,713-722,1998

[15] Donald F.Huelke and Cherles P.Compton, " The effect of seat belts on injury severity of frontal and rear seat occupants in the same frontal crash" vol .27 No 6, pp. 835-838,1995

[16] A. Hambali, S. M. Sapuan, N. Ismail, Y. Nukman, "Material selection of polymeric composite automotive bumper beam usinganalytical hierarchy process", Cent. South Univ. Technol. (2010) 17: 244-256 DOI: 10.1007/s11771-010-0038-y. 2010.

\section{BIOGRAPHIES}

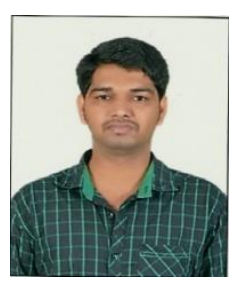

Name: SURESH BABU K

Email:suri903637@gmail.com

Designation: Student

Qualification: M.Tech (Machine Design)

Department: Mechanical Engg.

College: Brindavan college of Engg

Place: Bengaluru - 560063 


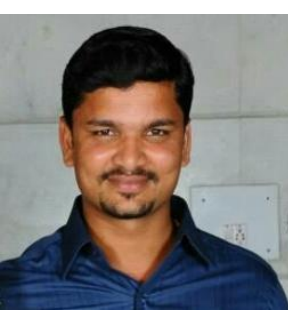

Name: SOMASHEKAR HK

Email:somashekarhk91@gmai.com

Designation: Assistant professor

Qualification: M.Tech (Machine

Design)

Department: Mechanical Engg.

College: Brindavan college of Engg

Place: Bengaluru - 560063

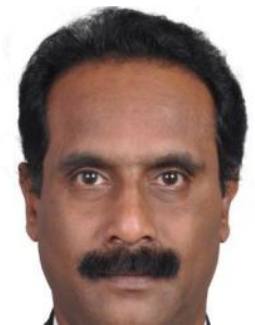

Name: Dr S PADMANABHA

Email: padduraj2000@gmail.com

Designation: Principal

Qualification: B.E, M.E, PhD,

MISTE

Department: Mechanical Engg.

College: Brindavan college of Engg

Place: Bengaluru - 560063 